\title{
Effects of tofacitinib monotherapy on patient-reported outcomes in a randomized phase 3 study of patients with active rheumatoid arthritis and inadequate responses to DMARDs
}

Vibeke Strand ${ }^{1,5}$, Joel Kremer ${ }^{2}$, Gene Wallenstein ${ }^{3 *}$, Keith S. Kanik ${ }^{3}$, Carol Connell ${ }^{3}$, David Gruben ${ }^{3}$, Samuel H. Zwillich ${ }^{3}$ and Roy Fleischmann ${ }^{4}$

\begin{abstract}
Introduction: Tofacitinib is an oral Janus kinase inhibitor for the treatment of rheumatoid arthritis.

Method: In this 6-month, phase 3, randomized, placebo-controlled trial, 611 patients with inadequate response to disease-modifying anti-rheumatic drugs (DMARD-IR) were randomized 4:4:1:1 to receive: tofacitinib $5 \mathrm{mg}$ BID or tofacitinib $10 \mathrm{mg}$ BID for the duration of the study, or placebo for 3 months followed by tofacitinib $5 \mathrm{mg}$ BID or tofacitinib 10 mg BID. Patient-reported outcomes (PROs) included: Patient Global Assessment of Disease Activity (PtGA); Patient Assessment of Pain (Pain); Health Assessment Questionnaire-Disability Index (HAQ-DI); Medical Outcomes Survey (MOS) Short Form-36 (SF-36); Functional Assessment of Chronic Illness Therapy-Fatigue (FACIT-F); and MOS Sleep Scale. Time-to-event data (PtGA and Pain) were collected using an interactive voice response system daily diary (baseline through day 14).
\end{abstract}

Results: At month 3, tofacitinib 5 and $10 \mathrm{mg}$ BID demonstrated statistically significant improvements versus placebo in PtGA (both $p<0.0001$ ), Pain (both $p<0.0001$ ), HAQ-DI (both $p<0.0001$ ), SF-36 Physical $(p<0.0001$ ) and Mental $(p<0.05$ [5 mg BID] and $p<0.0001$ [10 mg BID]), Component Summary scores and all domain scores $(p<0.05-p<0.0001)$ and FACIT-F (both $p<0.0001$ ). Statistically significant changes from baseline in MOS Sleep Scale were reported for $10 \mathrm{mg}$ BID $(p<0.05)$. Benefits of tofacitinib treatment were rapid in onset and significant improvements were reported at week 2 for PtGA, Pain and HAQ-DI, and differentiation from baseline was seen as early as 3 days after treatment initiation for interactive voice response system (IVRS) PtGA and IVRS Pain. The numbers needed to treat for patients to report changes greater than or equal to the minimum clinically important difference in PtGA, Pain, HAQ-DI, SF-36 Physical Component Summary score and FACIT-F ranged between 4.0-6.1 (5 mg BID) and 3.2-5.0 (10 mg BID).

Conclusion: Tofacitinib monotherapy in DMARD-IR patients resulted in statistically significant and clinically meaningful improvements in multiple PROs versus placebo at month 3, with sustained improvements over 6 months.

Trial registration: Clinicaltrials.gov registration NCT00814307, registered 22 December 2008

Keywords: Autoimmunity, Rheumatoid arthritis, Patient perspective

\footnotetext{
* Correspondence: Gene.wallenstein@pfizer.com

${ }^{3}$ Pfizer Inc, 445 Eastern Point Road, MS 8260-2515, Groton, CT 06340, USA

Full list of author information is available at the end of the article
}

(c) 2015 Strand et al. Open Access This article is distributed under the terms of the Creative Commons Attribution 4.0 International License (http://creativecommons.org/licenses/by/4.0/, which permits unrestricted use, distribution, and reproduction in any medium, provided you give appropriate credit to the original author(s) and the source, provide a link to the Creative Commons license, and indicate if changes were made. The Creative Commons Public Domain Dedication waiver (http://creativecommons.org/publicdomain/zero/1.0/) applies to the data made available in this article, unless otherwise stated. 


\section{Introduction}

Rheumatoid arthritis (RA) is a chronic autoimmune disease, which is characterized by systemic inflammation, persistent synovitis and joint destruction. RA represents a significant health and socioeconomic burden, and affects all domains of health-related quality of life (HRQoL), in particular physical functioning, pain, fatigue and physical and emotional roles [1, 2], which patients report are more important to them than joint counts and laboratory tests [3]. Both the US Food and Drug Administration and European Medicines Agency emphasize that patient-reported outcomes (PROs) selected for evaluation in a randomized controlled trial (RCT) should be targeted to the specific patient population $[4,5]$. The Outcomes Measures in Rheumatology (OMERACT) international consensus effort recommends use of disease-specific and generic instruments to assess physical function, HRQoL and fatigue in RCTs in RA [3, 6-8].

The goal of therapy should be to use a treat-to-target strategy to achieve remission, if possible, or low disease activity, while limiting joint destruction, maintaining physical function and optimizing HRQoL [9]. Standardof-care treatment includes conventional nonbiologic and/or biologic disease-modifying antirheumatic drugs (cDMARDs and bDMARDs, respectively) [10]. Patients who do not achieve remission, or low disease activity with advanced disease, with methotrexate and/or other cDMARDs are often escalated to treatment with bDMARDs (often in combination with cDMARDs), including cytokine inhibitors (tumor necrosis factor inhibitors, interleukin (IL)-6 inhibitors, IL-1 inhibitors), $\mathrm{B}$ cell inhibitors and B-T cell co-stimulation modulators $[9,11,12]$. As not all patients respond adequately to these medications, an unmet need for additional therapies persists, including those with alternative mechanisms of action.

Tofacitinib is an oral Janus kinase (JAK) inhibitor which preferentially inhibits signaling by heterodimeric receptors associated with JAK3 and/or JAK1, with functional selectivity over those that signal via pairs of JAK2 [13].

Administration of tofacitinib 5 and $10 \mathrm{mg}$ orally twice daily (BID) has demonstrated sustained efficacy with a manageable safety profile in patients with RA in phase 2 [14-18] and phase 3 [19-24] RCTs of up to 24 months' duration, and in long-term extension studies for up to 7 years $[25,26]$.

The phase 3 ORAL Solo RCT (A3921045) was designed to assess the efficacy and safety of tofacitinib monotherapy in patients with active RA, who had prior inadequate responses to cDMARDs or bDMARDs. The primary efficacy (including HAQ-DI) and safety data have been reported elsewhere [21], and showed that tofacitinib monotherapy results in reductions in signs and symptoms of active RA including improvement in physical function, with a manageable safety profile over 6 months. Here we present the complete profile of PROs from this phase 3 trial.

\section{Methods}

\section{Study design and treatment}

This was a phase 3, 6-month, placebo-controlled RCT (ClinicalTrials.gov NCT00814307; ORAL Solo), conducted at 94 centers worldwide (February 2009 to June 2010) in compliance with the Declaration of Helsinki and International Conference on Harmonisation Good Clinical Practice Guidelines. The final protocol was approved by Institutional Review Boards and/or Independent Ethics Committees at the investigational sites (Additional file 1: Table S1). Patients provided written, informed consent.

Details of the trial design and patient population are reported elsewhere [21]. Eligible patients were $\geq 18$ years old, with RA for $\geq 6$ months diagnosed by the American College of Rheumatology (ACR) 1987 Revised Criteria, with active disease ( $\geq 6$ tender joints and $\geq 6$ swollen joints; erythrocyte sedimentation rate $>28 \mathrm{~mm} / \mathrm{h}$ (measured in the local laboratory); and/or C-reactive protein $>7 \mathrm{mg} / \mathrm{L}$ ). Patients were required to have prior inadequate responses and/or intolerability to $\geq 1$ cDMARD or bDMARD (499 patients $(82.3 \%)$ had prior inadequate response to methotrexate). A 4-week washout of failed DMARDs was required (12 weeks for abatacept and tocilizumab). Stable doses of antimalarial drugs, non-steroidal anti-inflammatory drugs (NSAIDs), and corticosteroids ( $\leq 10 \mathrm{mg} /$ day prednisone equivalent) were permitted.

Patients were randomized 4:4:1:1 to receive tofacitinib $5 \mathrm{mg}$ BID or tofacitinib $10 \mathrm{mg}$ BID, or placebo for 3 months followed by tofacitinib $5 \mathrm{mg}$ BID or tofacitinib $10 \mathrm{mg}$ BID. At month 3, all placebo patients were switched blindly to active treatment and received tofacitinib for the next 3 months. Randomization was performed using an automated web/telephone system (Impala, Pfizer Inc, USA, New York, NY). The study was patient-blinded, investigator-blinded and sponsor-blinded.

\section{Assessment of patient-reported outcomes}

Patient Global Assessment of Disease Activity (PtGA) and Patient Assessment of Pain (Pain) were evaluated using the $100-\mathrm{mm}$ visual analog scale (VAS). Physical function was evaluated by the Health Assessment Questionnaire-Disability Index (HAQ-DI); HRQoL was evaluated by the Medical Outcomes Survey (MOS) Short Form-36 (SF-36; Version 2, Acute) questionnaire, which assesses eight domains (scores range from 0-100, with higher scores indicating better HRQoL): physical functioning (PF), role physical (RP), bodily pain (BP), general health $(\mathrm{GH})$, vitality $(\mathrm{VT})$, social functioning $(\mathrm{SF})$, role 
emotional (RE), and mental health (MH). Z-transformed and normalized domain scores are grouped into Physical Component Summary (PCS) and Mental Component Summary (MCS) scores. The Functional Assessment of Chronic Illness Therapy-Fatigue (FACIT-F) scale was used to assess fatigue/tiredness and the MOS Sleep Scale, the quality of sleep.

PtGA, Pain, and HAQ-DI were assessed at all time points (baseline, week 2, months 1, 2, 3, 4, 5, and 6, and/or early termination). Time-to-event data were collected using an interactive voice response system (IVRS) daily diary from baseline through day 14 for PtGA (IVRS) and IVRS Pain. Time-to-event data were only collected from patients in the USA. The SF-36, FACIT-F, and MOS Sleep Scale were assessed at baseline, months 3 and 6, and/or early termination. Changes from baseline were compared with published values for minimum clinically important differences (MCID): $\geq 10$ points in VAS PtGA and Pain [27-30], $\geq 0.22$ points in HAQ-DI [27], $\geq 2.5$ points, and $\geq 5$ points in SF-36 summary and domain scores, respectively, [31-36] and $\geq 4$ points in FACIT-F [37]. No MCID values have been determined for the MOS Sleep Scale.

\section{Disease activity}

The Disease Activity Score based on C-reactive protein and 28 tender joint count and 28 swollen joint count (DAS28-3(CRP)) was used for comparison with results from PROs, because DAS28-3(CRP) is not composed of any of the PROs of interest.

\section{Statistical analyses}

This manuscript focuses on the month 3 time point before placebo patients were switched to tofacitinib; analyses at 6 months examined whether improvements at 3 months in those receiving active therapy were sustained, and assessed changes following blinded switching of placebo patients to tofacitinib at 3 months. All analyses were based on the full analysis set, including all randomized patients who received at least one dose of study drug (modified intention to treat) with at least one post-baseline measurement. Furthermore, if a variable was expressed as change from baseline then there had to have been a non-missing baseline value.

Mean changes from baseline in continuous end points were expressed as least squares mean (LSM), and analyzed using a mixed-effects longitudinal model, which included effects of treatment and visit (geographic region of the investigative site, baseline value of the dependent variable, and the treatment-by-visit interaction), while patients were treated as a random effect.

The percentage of patients reporting improvements MCID was compared between tofacitinib and placebo groups using a normal approximation to the binomial (by forming a $z$ score) to calculate numbers needed to treat (NNT). NNT was considered to be statistically significant if the percentage of responders by the MCID differed statistically from placebo. Pearson correlations of changes from baseline at month 3 in DAS28-3(CRP) with changes from baseline in HAQ-DI, Pain, and PtGA were calculated.

Statistical significance was declared for $p \leq 0.05$, with no adjustment for multiple comparisons. Formal statistical comparisons between tofacitinib 5 and $10 \mathrm{mg}$ BID dose groups were not performed as the study was not powered for these subgroup comparisons.

\section{Results}

\section{Patients}

Between February 2009 and June 2010, 611 patients were randomized to receive tofacitinib $5 \mathrm{mg} \operatorname{BID}(\mathrm{n}=244)$, tofacitinib $10 \mathrm{mg}$ BID $(\mathrm{n}=245)$, placebo followed by tofacitinib $5 \mathrm{mg}$ BID $(n=61)$, and placebo followed by tofacitinib $10 \mathrm{mg} \operatorname{BID}(\mathrm{n}=61) ; 610$ patients received at least one dose of study drug and 555 (91.0\%) completed the trial [21]. Most patients were Caucasian and female, with a mean age of 49.7-52.4 years across treatment groups and mean disease duration of 7.7-8.6 years [21].

Baseline values for SF-36 PCS and MCS scores were approximately $2 \mathrm{SD}$ and $1 \mathrm{SD}$ (10 points) below the normative value of 50 points (based on age- and gendermatched US normative data specific to this study population). Baseline domain scores were lowest in PF and RP domains (47-49 points lower than age- and gendermatched normative data), followed by BP and $\mathrm{GH}$ domains (34-36 points lower), RE, SF, MH and VT. Age- and gender-matched US normative data specific to this study population are plotted in Fig. 1 and baseline domain scores are presented in Table 1 [38, 39].

\section{Patient-reported outcomes \\ Patient global assessment of disease activity}

At month 3, LSM changes from baseline were statistically significant with tofacitinib 5 and $10 \mathrm{mg}$ BID treatment versus placebo $(p<0.0001)$, and exceeded the MCID ( $\geq 10$ points) (Table 1 ; Fig. $2 a$ ). Statistically significant changes from baseline were evident at week 2 and months 1 and 2 for both doses of tofacitinib versus placebo (Fig. 2a; Additional file 2: Table S2) and further improvements occurred through month 6 . Significantly more patients receiving tofacitinib reported improvements $\geq$ the MCID versus placebo (Fig 3a; Additional file 3: Table S3). Sequential decreases from baseline in IVRS PtGA occurred from approximately 3 days post-baseline (Fig. 4a), with greatest improvements observed in the $10 \mathrm{mg}$ BID group from 6-15 days post-baseline. Placebo patients who were switched to tofacitinib reported clinically meaningful changes between months 3 and 6 (Table 1). 
a) Placebo, Baseline and Month 3

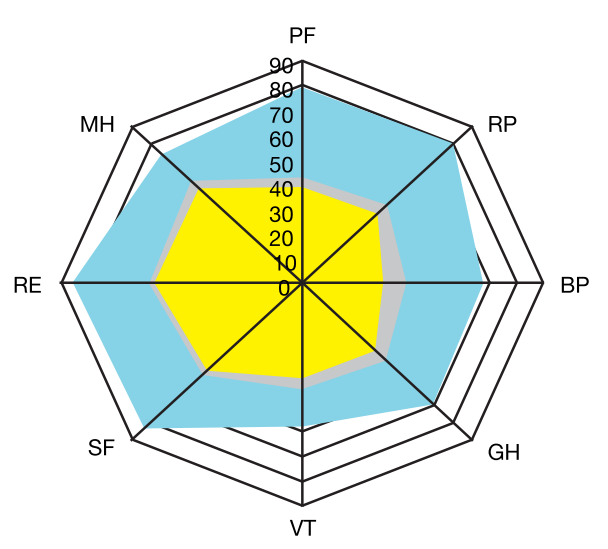

b) Tofacitinib $5 \mathrm{mg}$ BID, Baseline and Month 3

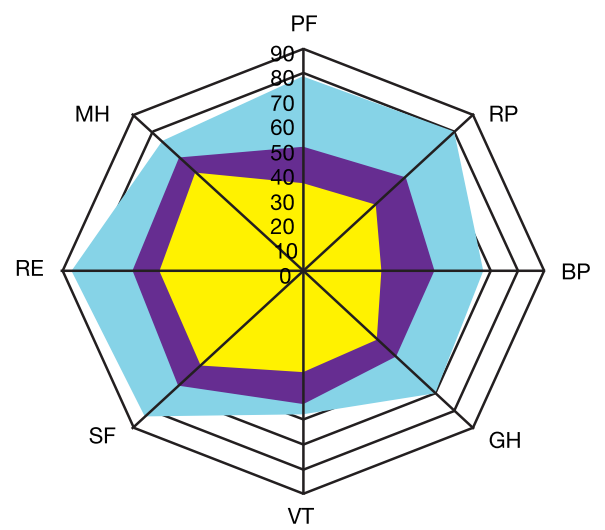

d) Baseline Placebo, Tofacitinib 5 and 10 mg BID

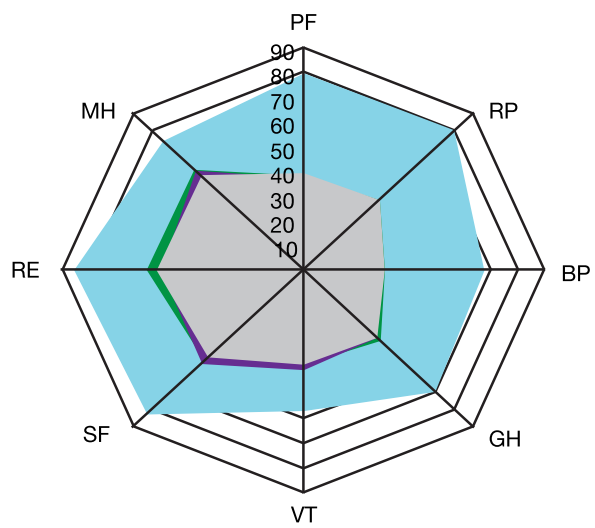

Age- and gender-matched US normative data specific to this study

Baseline*

Placebo

Tofacitinib $5 \mathrm{mg}$ BID

Tofacitinib $10 \mathrm{mg}$ BID

c) Tofacitinib $10 \mathrm{mg}$ BID, Baseline and Month 3

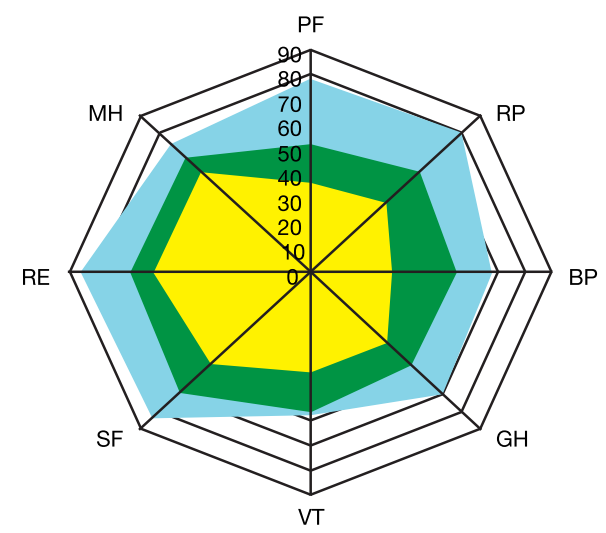

e) Combined Baseline, and Month 3 Placebo, Tofacitinib 5 and $10 \mathrm{mg}$ BID

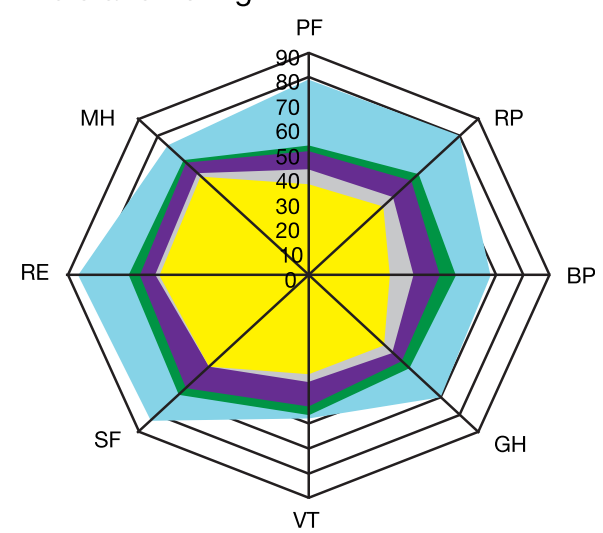

Fig. 1 Short Form-36 (SF-36) domain scores at month 3. Spydergrams of SF-36 domain scores at month 3, with a US age- and gender-matched normative population as a comparator. a Placebo at baseline and month 3. b Tofacitinib $5 \mathrm{mg}$ twice daily (BID) at baseline and month 3. c Tofacitinib $10 \mathrm{mg} \mathrm{BID}$ at baseline and month 3. d Baseline scores for each treatment group. e Weighted combined baseline score + placebo + tofacitinib $5 \mathrm{mg}$ BID + tofacitinib $10 \mathrm{mg}$ BID. a-d Treatment group baselines (using separate colors in $\mathbf{d}$ ). e Weighted combined baseline across all treatment groups. Placebo, $n=122$ at baseline, and $n=108$ at month 3; tofacitinib 5 mg BID, $n=239$ at baseline and $n=235$ at month 3; tofacitinib 10 mg, $n=243$ at baseline and $n=224$ at month 3. Study values were normalized using means and SDs. See Ware et al. [38]. BP bodily pain, GH general health, $M H$ mental health, $P F$ physical function, $R E$ role emotional, $R P$ role physical, SF social functioning, $V T$ vitality 
Table 1 Baseline values and changes from baseline at months 3 and 6 for patient-reported outcome measures

\begin{tabular}{|c|c|c|c|c|c|c|c|c|c|c|}
\hline & \multicolumn{3}{|c|}{ Baseline mean (SD) } & \multicolumn{3}{|c|}{ Month 3 LSM change from baseline (SE) } & \multicolumn{4}{|c|}{ Month 6 LSM change from baseline (SE) } \\
\hline & $\begin{array}{l}\text { Placebo } \\
(n=122)\end{array}$ & $\begin{array}{l}\text { Tofacitinib } 5 \mathrm{mg} \\
\text { BID }(n=243)\end{array}$ & $\begin{array}{l}\text { Tofacitinib } 10 \mathrm{mg} \\
\text { BID }(n=245)\end{array}$ & $\begin{array}{l}\text { Placebo } \\
(n=122)\end{array}$ & $\begin{array}{l}\text { Tofacitinib } 5 \mathrm{mg} \\
\text { BID }(n=243)\end{array}$ & $\begin{array}{l}\text { Tofacitinib } 10 \mathrm{mg} \\
\text { BID }(n=245)\end{array}$ & $\begin{array}{l}\text { Placebo } \rightarrow \text { Tofacitinib } \\
5 \mathrm{mg} \mathrm{BID}(\mathrm{n}=61)\end{array}$ & $\begin{array}{l}\text { Placebo } \rightarrow \text { Tofacitinib } \\
10 \mathrm{mg} \mathrm{BID}(n=61)\end{array}$ & $\begin{array}{l}\text { Tofacitinib } 5 \mathrm{mg} \\
\text { BID }(n=243)\end{array}$ & $\begin{array}{l}\text { Tofacitinib } 10 \mathrm{mg} \\
\text { BID }(n=245)\end{array}$ \\
\hline PtGA & $62.63(21.91)$ & $61.66(22.00)$ & $63.46(23.23)$ & $-11.19(2.10)$ & $-26.99(1.45)^{* * *}$ & $-30.94(1.47)^{* * *}$ & $-28.07(2.97)$ & $-29.62(3.05)$ & $-30.25(1.47)$ & $-33.99(1.50)$ \\
\hline Pain & $61.79(21.27)$ & $61.35(22.27)$ & $62.03(23.63)$ & $-10.71(2.14)$ & $-26.94(1.47)^{* * *}$ & $-31.06(1.50)^{* * *}$ & $-26.01(3.02)$ & $-29.48(3.10)$ & $-29.19(1.49)$ & $-34.11(1.52)$ \\
\hline $\mathrm{HAQ}-\mathrm{DI}^{+}$ & $1.53(0.65)$ & $1.53(0.66)$ & $1.50(0.64)$ & $-0.19(0.05)$ & $-0.50(0.03)^{* * *}$ & $-0.57(0.03)^{* * *}$ & $-0.43(0.07)$ & $-0.59(0.07)$ & $-0.62(0.03)$ & $-0.67(0.04)$ \\
\hline \multicolumn{11}{|l|}{$\begin{array}{l}\text { SF-36 component } \\
\text { summary scores }\end{array}$} \\
\hline SF-36 PCS score & $32.21(8.35)$ & $31.23(8.03)$ & $31.37(7.39)$ & $2.63(0.78)$ & $6.79(0.53)^{* * *}$ & $8.55(0.55)^{* * *}$ & $5.18(1.09)$ & $6.14(1.11)$ & $8.01(0.53)$ & $9.66(0.55)$ \\
\hline SF-36 MCS score & $39.87(11.62)$ & $41.36(11.68)$ & $42.19(12.44)$ & $1.09(0.89)$ & $4.11(0.61)^{*}$ & $5.39(0.62)^{* * *}$ & $3.83(1.23)$ & $8.01(1.26)$ & $4.62(0.60)$ & $4.80(0.62)$ \\
\hline \multicolumn{11}{|l|}{ SF-36 domain scores } \\
\hline Physical functioning & $31.41(9.66)$ & $30.09(9.31)$ & $30.51(8.76)$ & $2.17(0.88)$ & $6.15(0.60)^{* *}$ & $6.97(0.62)^{* * *}$ & $4.02(1.22)$ & $5.15(1.26)$ & $6.95(0.60)$ & $8.17(0.62)$ \\
\hline Role physical & $33.33(8.97)$ & $32.84(8.87)$ & $33.45(8.69)$ & $1.88(0.83)$ & $5.89(0.57)^{* * *}$ & $7.53(0.58)^{* * *}$ & $4.33(1.16)$ & $6.31(1.20)$ & $7.01(0.57)$ & $7.85(0.59)$ \\
\hline Bodily pain & $32.77(7.67)$ & $32.41(7.57)$ & $32.74(7.55)$ & $3.91(0.86)$ & $8.26(0.58)^{* * *}$ & $10.84(0.60)^{* * *}$ & $7.88(1.21)$ & $10.28(1.25)$ & $9.44(0.59)$ & $11.30(0.61)$ \\
\hline General health & $34.70(9.00)$ & $34.86(8.72)$ & $35.71(8.86)$ & $2.44(0.75)$ & $4.76(0.51)^{*}$ & $6.34(0.53)^{* * *}$ & $5.26(1.06)$ & $5.37(1.10)$ & $6.51(0.52)$ & $7.49(0.54)$ \\
\hline Vitality & $40.13(9.82)$ & $41.22(10.06)$ & $41.04(10.27)$ & $2.03(0.81)$ & $6.56(0.55)^{* * *}$ & $8.49(0.57)^{* * *}$ & $4.67(1.15)$ & $8.27(1.18)$ & $6.87(0.56)$ & $8.30(0.58)$ \\
\hline Social functioning & $35.16(10.34)$ & $36.78(11.04)$ & 36.07 (11.27) & $0.62(0.91)$ & $5.29(0.62)^{* * *}$ & $7.51(0.64)^{* * *}$ & $3.54(1.29)$ & $8.21(1.34)$ & $6.05(0.63)$ & $6.83(0.65)$ \\
\hline Role emotional & $35.17(13.11)$ & $34.26(12.63)$ & 36.70 (13.03) & $1.20(1.05)$ & $4.07(0.72)^{*}$ & $5.50(0.74)^{* *}$ & $4.54(1.43)$ & $6.96(1.47)$ & $5.95(0.70)$ & $5.56(0.72)$ \\
\hline Mental health & $38.43(12.36)$ & 40.05 (11.49) & $40.50(12.57)$ & $2.19(0.88)$ & $4.71(0.60)^{*}$ & $5.52(0.62)^{*}$ & $4.09(1.23)$ & $8.02(1.27)$ & $4.52(0.60)$ & $5.35(0.62)$ \\
\hline FACIT-F & $27.17(10.88)$ & $27.90(10.70)$ & $27.72(11.15)$ & $2.84(0.82)$ & $6.70(0.56)^{* * *}$ & $8.01(0.58)^{* * *}$ & $6.57(1.16)$ & $9.11(1.20)$ & $6.98(0.57)$ & $8.63(0.58)$ \\
\hline MOS Sleep Scale & $47.32(21.24)$ & $42.45(18.38)$ & 43.09 (20.41) & $-4.81(1.48)$ & $-7.13(1.02)$ & $-10.18(1.04)^{*}$ & $-8.43(2.06)$ & $-10.50(2.14)$ & $-7.48(1.02)$ & $-9.98(1.05)$ \\
\hline
\end{tabular}

${ }^{\dagger}$ Co-primary endpoint at month $3 .{ }^{*} p<0.05 ;{ }^{*} p<0.001 ;{ }^{* * *} p<0.0001$ vs placebo. BID twice daily, FACIT-F Functional Assessment of Chronic IIIness Therapy-Fatigue, HAQ-DI Health Assessment QuestionnaireDisability Index, LSM least squares mean, MCS Mental Component Summary, MOS Medical Outcomes Study, Pain Patient Global Assessment of Pain, PCS Physical Component Summary, PtGA Patient Global Assessment of Disease Activity, SD standard deviation, SE standard error, SF-36 Short Form-36 


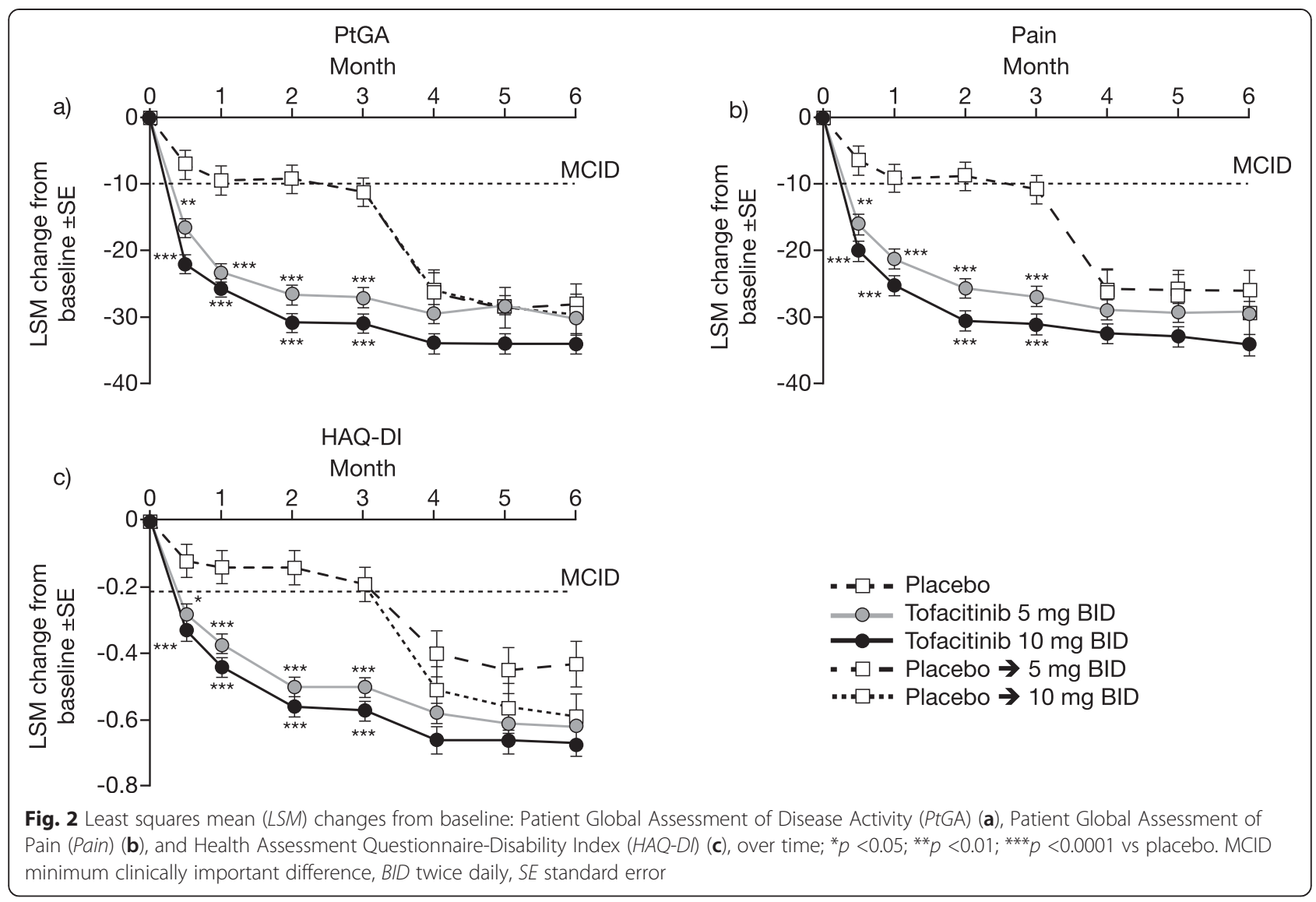

Improvements and the percentage of patients reporting improvements $\geq$ the MCID at month 3 were numerically greater for $10 \mathrm{mg}$ BID compared with $5 \mathrm{mg}$ BID, with a lower NNT (3.8 vs 4.0) (Fig. 3a; Additional file 3: Table S3). NNT over time for PtGA compared with ACR20/50/70 and DAS28-3(CRP) are shown in Additional file 4: Figure S1. Correlation at month 3 with DAS28-3(CRP) (both expressed as LSM changes from baseline) ranged from 0.32 (tofacitinib $10 \mathrm{mg}$ BID) to 0.51 (placebo); all were statistically significant.

\section{Pain}

At month 3, LSM changes from baseline were statistically significant in patients receiving tofacitinib 5 and $10 \mathrm{mg}$ BID versus placebo $(p<0.0001)$, and exceeded the MCID (Table 1; Fig. 2b). Statistically significant changes from baseline were also reported at week 2 and months 1 and 2 for both doses of tofacitinib versus placebo (Fig. 2b; Additional file 2: Table S2) and further improvement occurred through month 6 in both active treatment groups (Table 1). Significantly more patients receiving tofacitinib reported improvements $\geq$ the MCID versus placebo (Fig. 3b; Additional file 3: Table S3). Patients reported sequential decreases in IVRS Pain from approximately 3 days post-baseline (Fig. 4b); more patients in the $10 \mathrm{mg}$ BID group reported sustained improvements from 4-13 days post-baseline but formal statistical analyses between $5 \mathrm{mg}$ BID and $10 \mathrm{mg}$ BID were not performed. Placebo patients who were switched to tofacitinib reported clinically meaningful changes between months 3 and 6 (Table 1). Improvements in LSM values and the percentage of patients reporting improvements $\geq$ the MCID at month 3 were numerically greater in the $10 \mathrm{mg}$ BID group compared with $5 \mathrm{mg}$ BID group, with a lower NNT (3.5 vs 4.6) (Table 1; Fig. 3b; Additional file 3: Table S3). The NNT over time for pain compared with ACR20/50/ 70 and DAS28-3(CRP) are shown in Additional file 4: Figure S1. Correlations with DAS28-3(CRP) at month 3 (both expressed as LSM changes from baseline) ranged from 0.32 (tofacitinib $10 \mathrm{mg}$ BID) to 0.46 (placebo); all were statistically significant.

\section{Health assessment questionnaire-disability index}

At month 3, LSM changes from baseline were statistically significant for tofacitinib 5 and $10 \mathrm{mg}$ BID versus placebo $(p<0.0001)$, and exceeded the MCID $(\geq 0.22$ points) (Table 1; Fig. 2c). Statistically significant changes from baseline were also reported at week 2 (first postbaseline assessment) and months 1 and 2 for tofacitinib 5 and $10 \mathrm{mg}$ BID versus placebo (Fig. 2c; Additional file 2: 


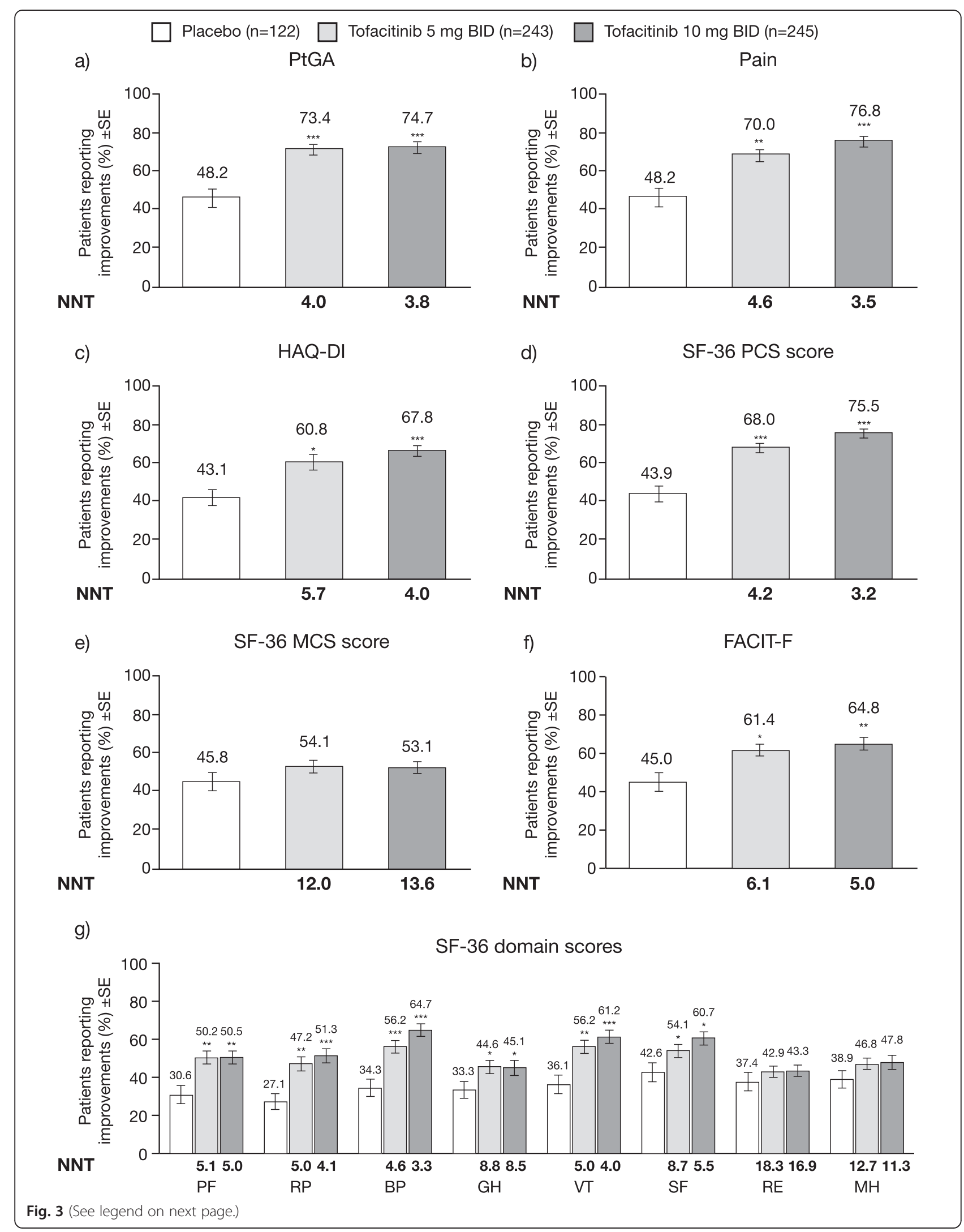


(See figure on previous page.)

Fig. 3 Percentage of patients with improvements $\geq$ the minimal clinically important difference (MCID) at month 3. Patient Global Assessment of Disease Activity (PtGA) (a), Patient Global Assessment of Pain (Pain) (b), Health Assessment Questionnaire-Disability Index (HAQ-Dl) (c), Short Form-36 Physical Component Summary (SF-36 PCS) score (d), SF-36 Mental Component Summary (MCS) score (e), Functional Assessment of Chronic IIIness Therapy-Fatigue (FACIT-F) (f) and SF-36 domain scores $(\mathbf{g}) ;{ }^{*} p<0.05 ;{ }^{* *} p<0.01 ;{ }^{* * *} p<0.0001$ vs placebo. MCID $\geq 10$ points in PtGA and Pain, $\geq 0.22$ points in HAQ-DI, $\geq 2.5$ points and $\geq 5$ points in SF-36 summary and domain scores, respectively and $\geq 4$ points in FACIT-F. BID twice daily, BP bodily pain, GH general health, MH mental health, NNT number needed to treat, PF physical function, RE role emotional, RP role physical, SE standard error, SF social functioning, VT vitality

Table S2) and further improvements accrued through month 6 (Table 1). Significantly more patients treated with tofacitinib reported improvements $\geq$ the MCID compared with placebo (Fig. 3c; Additional file 3: Table S3). Placebo patients advanced to tofacitinib reported clinically meaningful changes between month 3 and month 6 (Table 1). Improvements in LSM values and the percentage of patients reporting improvements $\geq$ the MCID at month 3 were numerically greater in the $10 \mathrm{mg}$ BID compared with the $5 \mathrm{mg}$ BID group, with a lower NNT (4.0 vs 5.7) (Table 1; Fig. 3c; Additional file 3: Table S3). The NNT over time for HAQ-DI compared with ACR20/ 50/70 and DAS28-3(CRP) are shown in Additional file 4:
Figure S1. Numerically more patients reported values consistent with normative scores in HAQ-DI $(\leq 0.5)$ with tofacitinib 5 and $10 \mathrm{mg}$ BID versus placebo (Additional file 5: Table S4). Correlations with DAS28-3(CRP) at month 3 ranged from 0.37 with tofacitinib $5 \mathrm{mg}$ BID to 0.47 with placebo; all were statistically significant.

\section{Health-related quality of life assessed by Short Form-36}

LSM changes from baseline in SF-36 PCS and MCS scores were statistically significant for $5 \mathrm{mg} \operatorname{BID}(p<0.0001$ and $p<0.05$, respectively) and $10 \mathrm{mg}$ BID (both $p<0.0001$ ) compared with placebo at month 3 (first post-baseline assessment), and exceeded the MCID ( $\geq 2.5$ points) (Table 1 ).

\section{$\longrightarrow$ Placebo $(n=122) \multimap$ Tofacitinib $5 \mathrm{mg}$ BID $(n=243) \multimap$ Tofacitinib $10 \mathrm{mg}$ BID $(n=245)$}

a)

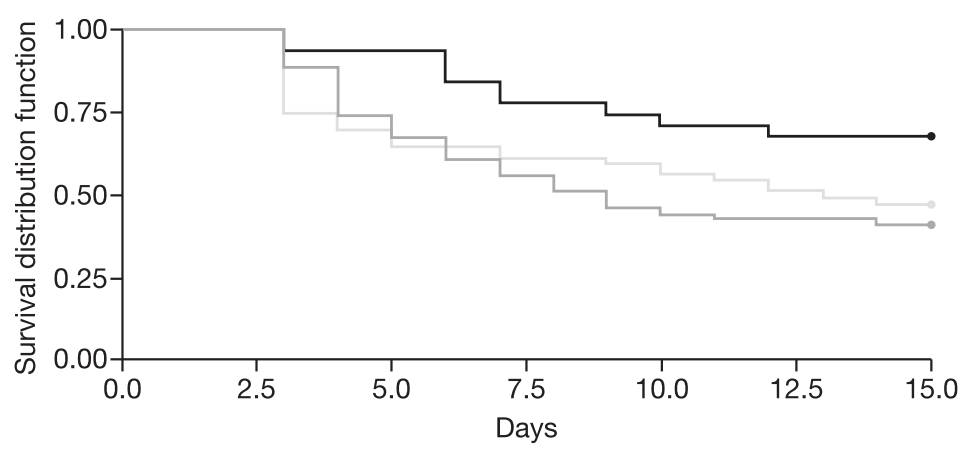

b)

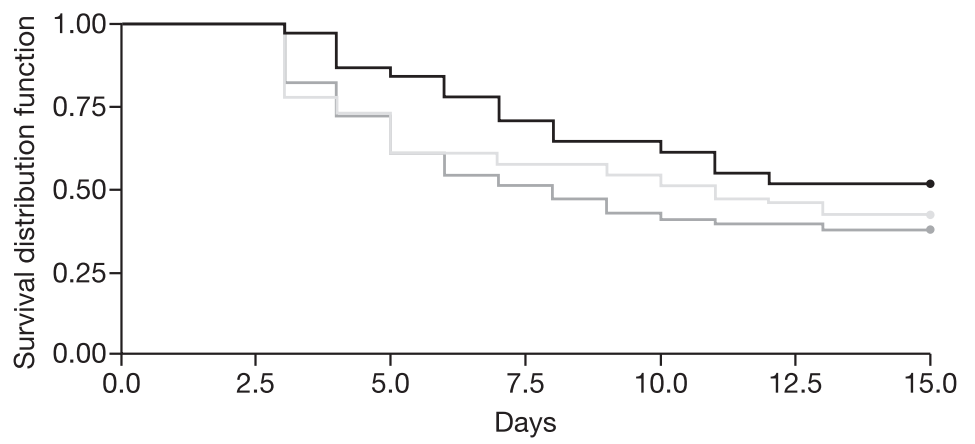

Fig. 4 Time to first sequential decrease from baseline. Interactive voice response system (IVRS) Patient Global Assessment of Disease Activity (PtGA) (a) and IVRS Patient Global Assessment of Pain (Pain) (b). A sequential decrease was defined as at least 2 days of consecutive improvement in each measure. BID twice daily 
Significantly more patients in the tofacitinib treatment groups reported improvements $\geq$ the MCID in PCS scores versus placebo (Fig. 3d); the percentage of patients reporting improvements $\geq$ the MCID in MCS scores were not statistically significant for the tofacitinib treatment groups versus placebo (Fig. 3e). LSM changes from baseline and the percentage of patients reporting improvements $\geq$ the MCID at month 3 were numerically greater for $10 \mathrm{mg}$ BID compared with $5 \mathrm{mg}$ BID, with a lower NNT (PCS: 3.2 vs 4.2; MCS: 12.0 vs 13.6) (Table 1; Fig. 3d, e).

Changes from baseline in SF-36 domain scores compared with age and gender US normative data are presented in Fig. 1. At month 3, patients receiving tofacitinib reported statistically significant $(p<0.05$ to $p<0.0001$ ) and clinically meaningful improvements ( $\geq 5$ points) from baseline in all domain scores (Table 1 ). Compared with placebo, significantly more patients receiving tofacitinib reported improvements $\geq$ the MCID ( $\geq 5$ points) in the PF, RP, BP GH, VT, and SF domains (Fig. 3g). The percentage of patients reporting improvements meeting or exceeding US normative SF-36 scores for both tofacitinib doses compared with placebo are presented in Additional file 6: Figure S2.

\section{Functional assessment of chronic illness therapy-fatigue}

Statistically significant improvements from baseline were observed in the tofacitinib groups for FACIT-F $(p<0.0001)$ at month 3 (first post-baseline assessment) (Table 1). Significantly more patients receiving tofacitinib reported improvements $\geq$ the MCID ( $\geq 4$ points) versus placebo (Fig. 3f). Further improvements occurred through month 6 in the active treatment groups (Table 1). Placebo patients who switched to tofacitinib reported clinically meaningful changes between months 3 and 6 (Table 1). LSM values and the percentage of patients reporting improvements $\geq$ the MCID at month 3 were numerically greater in the $10 \mathrm{mg}$ BID group compared with the $5 \mathrm{mg}$ BID group, with a lower NNT (5.0 vs 6.1) (Table 1; Fig. 3f).

\section{Medical outcomes study sleep scale}

Statistically significant changes from baseline in the MOS Sleep Scale were evident at month 3 (first postbaseline assessment) for tofacitinib $10 \mathrm{mg} \operatorname{BID}(p<0.05)$ but not for tofacitinib $5 \mathrm{mg}$ BID $(\mathrm{p}=0.1926)$ versus placebo (Table 1). Further improvements occurred through month 6 in patients receiving active treatment, and similar changes from months 3-6 were reported by placebo patients who switched to tofacitinib (Table 1).

\section{Discussion}

It has been demonstrated that PROs provide quantitative data of comparable value to more traditional measures (e.g., joint counts and laboratory tests), discriminate treatment effects, are easy to perform, and are important for long-term health outcomes [40]. Furthermore, HRQoL measures are unique in that they measure the impact of the underlying disease, treatment-related benefits and adverse effects, and offer the opportunity for comparison to other disease populations. PROs, clinical assessments and imaging of joints are all important in assessing RA patients and their responses to treatment, and should be utilized together to provide a holistic view of disease activity and wellbeing.

In this phase 3 trial, DMARD-IR patients receiving tofacitinib 5 and $10 \mathrm{mg}$ BID monotherapy reported statistically significant and clinically meaningful improvements in PtGA, Pain, HAQ-DI, HRQoL, and fatigue at 3 months, with significant changes versus placebo observed at the first time point measured post-baseline, as early as 2 weeks. This is particularly important as patients were expected to have active disease at the time they initiated protocol treatment. In those patients continuing tofacitinib therapy, further improvements in LSM values were reported at month 6, and improvements in LSM values were greater for 10 versus $5 \mathrm{mg}$ BID. Placebo patients who switched to tofacitinib at month 3 reported improvements through month 6 , confirming the results of the primary analysis at 3 months. Benefits of treatment with tofacitinib, as demonstrated by these PROs, were consistent with primary efficacy data, which showed statistically significant improvements in ACR responses, and changes from baseline in HAQ-DI with tofacitinib 5 and $10 \mathrm{mg}$ BID monotherapy versus placebo [21].

Improvements in PtGA, Pain, and HAQ-DI with tofacitinib versus placebo were similar, and consistent with changes reported for fatigue and HRQoL. Across all five of these PROs - PtGA, Pain, HAQ-DI, SF-36 PCS, and FACIT-F - the proportion of patients reporting improvements $\geq$ the MCID ranged from $61-73 \%$ for $5 \mathrm{mg}$ BID and $65-77 \%$ for $10 \mathrm{mg}$ BID. Improvements in LSM changes from baseline to months 3 and 6 , and from 3 to 6 months in placebo patients switched to tofacitinib, were consistently greater for $10 \mathrm{mg}$ BID versus $5 \mathrm{mg}$ BID. Across these five PROs, the NNT values for treatment with $10 \mathrm{mg}$ BID ranged from 3.2-5.0 compared with 4.0-6.1 for $5 \mathrm{mg}$ BID, with such low numbers reflecting the value of therapy to patients.

In active RA, physical functioning, pain and fatigue have been shown to be important outcomes from the patient's perspective [41] Tofacitinib therapy resulted in improvements in each of these aspects of the disease, measured by PtGA, Pain, HAQ-DI, FACIT-F, and the MOS Sleep Scale. Benefits of tofacitinib treatment were rapid in onset and significant improvements were reported at week 2 for PtGA, Pain, and HAQ-DI, and differentiation from baseline was seen as early as 3 days after treatment initiation for IVRS PtGA and IVRS Pain. 
As expected, patients reported substantially diminished HRQoL at baseline, measured by SF-36, versus age- and gender-matched US normative data as a benchmark comparison (Fig. 1). This was particularly evident in the PF, $\mathrm{RP}, \mathrm{BP}, \mathrm{GH}, \mathrm{SF}$, and RE domains, consistent with the broad impact of active RA on physical, social, emotional, and mental functioning. Following tofacitinib treatment, patients reported statistically significant and clinically meaningful improvements in both summary scores and all domains of the SF-36 with both tofacitinib doses.

Statistically significant and clinically meaningful improvements in the VT domain resulted in scores that approached (5 mg BID) and met (10 mg BID) normative values from the US general population at month 3 . These are reflected by improvements in the FACIT-F scores, which were statistically significantly greater versus placebo, and exceeded the MCID. Not only were changes from baseline greatest in those domains with the lowest scores at baseline (PF, RP, and $\mathrm{BP})$, but improvements were also evident in other domains, including RE and $\mathrm{MH}$, which correlate strongly with the classic instruments used to diagnose clinical depression. RA is known to have a major negative psychological impact, with depression occurring in 13-20\% of patients [42] or more [43] based on clinical assessments. Thus, it appears that tofacitinib not only improves physical functioning, pain and fatigue, but also social and emotional functioning and wellbeing.

Patients receiving placebo monotherapy improved at 3 months, although mean improvements were small in magnitude: below the MCID in the HAQ-DI and FACIT-F, and meeting the MCID in the PtGA, Pain, and PCS scores. Fewer than $50 \%$ of placebo patients reported changes the MCID (43-48 \%) in all PRO endpoints compared with $\geq 61 \%$ and $\geq 68 \%$ in the 5 and $10 \mathrm{mg}$ BID groups, respectively.

\section{Conclusions}

This phase 3 randomized clinical trial, ORAL Solo, demonstrates that treatment with tofacitinib monotherapy for 3 months provides relief from the broad burden of active RA, favorably impacting a wide range of PROs. These include self-assessment of physical function, pain, disease activity, and HRQoL, with low NNT and early onset of improvement in patients with a prior inadequate response to CDMARDs and/or bDMARDs.

\section{Additional files}

Additional file 1: Table S1. Ethical review boards and study centers. (DOCX $35 \mathrm{~kb}$ )

Additional file 2: Table S2. Baseline and changes from baseline by visit prior to month 3 for patient-reported outcome measures; ${ }^{*} p<0.01$; ${ }^{* *} p<0.001 ;{ }^{* * *} p<0.0001$ vs placebo. ${ }^{a} n=237 ;{ }^{b} n=240 ;{ }^{c} n=237 ;{ }^{d} n=238$; ${ }^{e} n=231 ;{ }^{f}=241 ;{ }^{g} n=243$. BID twice daily, HAQ-D/ Health Assessment
Questionnaire-Disability Index, LSM least squares mean, Pain Patient Global Assessment of Pain, PtGA Patient Global Assessment of Disease Activity, SD standard deviation, SE standard error. (DOCX $13 \mathrm{~kb}$ )

Additional file 3: Table S3. Rates reports of improvements meeting or exceeding clinically meaningful and normative values in both a patientreported outcome (PRO) and DAS28-(CRP) at month $3 ;{ }^{*} p \leq 0.05,{ }^{* *} p \leq 0.01$, ${ }^{* * *} p \leq 0.0001$ versus placebo. BID twice daily, DAS28-3(CRP) Disease Activity Score based on $C$ reactive protein and 28 tender joint count and 28 swollen joint count, HAQ-DI Health Assessment Questionnaire-Disability Index, NNT number needed to treat versus placebo, MCID minimally clinically important difference. (DOCX $15 \mathrm{~kb}$ )

Additional file 4: Figure S1. Numbers needed to treat for ACR 20/50/ 70 (a), Disease Activity Score based on C reactive protein and 28 tender joint count and 28 swollen joint count (DAS28-3(CRP)) improvement of 1.2 and 0.6 (b), HAQ-DI $\leq 0.5$ (c), patient global assessment (d), and pain (e) $\geq$ the minimal clinically important difference $(M C I D)$ for tofacitinib 5 and $10 \mathrm{mg}$ twice daily (BID). (DOC $146 \mathrm{~kb}$ )

Additional file 5: Table S4. Rates of reporting normative values for the Health Assessment Questionnaire-Disability Index (HAQ-DI) $(\leq 0.5)$ per visit; ${ }^{*} p \leq 0.05,{ }^{* *} p \leq 0.01,{ }^{* * *} p \leq 0.0001$ versus placebo. BID twice daily, $\mathrm{Cl}$ confidence interval on the estimate of the rate. (DOCX $12 \mathrm{~kb}$ )

Additional file 6: Figure S2. Rates of reporting improvements meeting or exceeding US normative Short Form-36 (SF-36) scores, in comparison with placebo. (DOC $120 \mathrm{~kb}$ )

\section{Abbreviations}

ACR: American College of Rheumatology; bDMARD: biologic disease-modifying antirheumatic drug; BP: bodily pain; CDMARD: non-biologic DMARD; BID: twice daily; FACIT-F: Functional Assessment of Chronic Illness Therapy-Fatigue; GH: General health; HAQ-DI: Health Assessment Questionnaire-Disability Index; HRQoL: health-related quality of life; IVRS: interactive voice response system; LSM: least squares mean; MCID: minimum clinically important difference; MCS: Mental Component Summary; MH: mental health; MOS: Medical Outcomes Study; NNT: number needed to treat; NSAID: non-steroidal anti-inflammatory drug; Pain: Patient Global Assessment of Pain; PCS: Physical Component Summary; PF: physical functioning; PRO: patient-reported outcome; PtGA: Patient Global Assessment of Disease Activity; RA: rheumatoid arthritis; RE: role emotional; RP: role physical; SD: standard deviation; SE: standard error; SF: social functioning; SF-36: Short Form-36; VAS: visual analog scale; VT: vitality.

\section{Competing interests}

$\checkmark$ Strand has served as a consultant for AbbVie, Amgen, Biogen Idec, Biotest, BMS, Celltrion, Genentech/Roche, Hospira, Incyte, Janssen, Lilly, Novartis, Pfizer, Regeneron, Sanofi, Takeda, UCB and Vertex. J Kremer has served as a consultant for, and has received research support from, AbbVie, Amgen, BMS, Genentech, Pfizer Inc, and UCB, and has received payment for lectures, including service on speakers' bureaus, from AbbVie. R Fleischmann has served as a consultant for, and has received research grants from AbbVie, Amgen, Astra-Zeneca, BMS, Lilly, Pfizer Inc, Roche, Sanofi-Aventis and UCB. G Wallenstein, C Connell, J Bradley, D Gruben, and SH Zwillich are employees of Pfizer Inc and hold stock/stock options in Pfizer Inc. KS Kanik is an employee of Pfizer Inc, holds stock/stock options in Pfizer Inc, and is named as a co-inventor on a patent related to the use of tofacitinib. None of the authors have non-financial conflicts of interest to declare.

\section{Authors' contributions}

VS, GW, CC, SHZ, and KSK were involved in the conception, design of the study and/or analyses, and were involved in data interpretation; they were also involved in drafting and critically reviewing the manuscript. JK and RF were involved in the conception, design of the study and/or analyses, and were involved in data collection and interpretation; they were also involved in drafting and critically reviewing the manuscript. DG was involved in the conception, design of the study and/or analyses, was responsible for data analysis and was involved in data interpretation; he was also involved in drafting and critically reviewing the manuscript. All authors approved the final draft prior to submission. 


\section{Acknowledgments}

The authors would like to thank the patients who were involved in this study, and the A3921045 investigators and study team. The authors would also like to thank Vivianne Dillon and Jill Lundberg (clinical project managers), and Allison Brailey (lead programmer). This study was funded by Pfizer Inc. Editorial support under the direction of the authors was provided by Karen Irving and Anne Marie Reid, PhD, at Complete Medical Communications and was funded by Pfizer Inc.

\section{Author details}

${ }^{1}$ Biopharmaceutical Consultant, Portola Valley, CA, USA. ${ }^{2}$ Center for Rheumatology, Albany Medical College, Albany, NY, USA. ${ }^{3}$ Pfizer Inc, 445 Eastern Point Road, MS 8260-2515, Groton, CT 06340, USA. ${ }^{4}$ Metroplex Clinical Research Center, Dallas, TX, USA. ${ }^{5}$ Stanford University, Palo Alto, CA, USA.

Received: 18 December 2014 Accepted: 16 October 2015 Published online: 04 November 2015

\section{References}

1. Strand V, Singh JA. Newer biological agents in rheumatoid arthritis: impact on health-related quality of life and productivity. Drugs. 2010;70:121-45.

2. Strand $V$, Khanna D. The impact of rheumatoid arthritis and treatment on patients' lives. Clin Exp Rheumatol. 2010;28:S32-40.

3. Kirwan JR, Hewlett SE, Heiberg T, Hughes RA, Carr M, Hehir M, et al. Incorporating the patient perspective into outcome assessment in rheumatoid arthritis-progress at OMERACT 7. J Rheumatol. 2005;32:2250-6.

4. US Dept of Health, FDA, CDER C, CDRH. Guidance for Industry Patient-Reported Outcome Measures. In: Use in Medical Product Development to Support Labeling Claims. 2009. p. 1-39.

5. European Medicines Agency: Reflection Paper on the Regulatory Guidance for the Use of Health-Related Quality of Life (HRQL) Measures in the Evaluation of Medicinal Products [http://www.ispor.org/workpaper/emeahrql-guidance.pdf].

6. Bellamy N, Boers M, Felson D, Fries J, Furst D, Henry D, et al. Health status instruments/utilities. J Rheumatol. 1995;22:1203-7.

7. Kirwan JR, Minnock P, Adebajo A, Bresnihan B, Choy E, de Wit M, et al. Patient perspective: fatigue as a recommended patient centered outcome measure in rheumatoid arthritis. J Rheumatol. 2007:34:1174-7.

8. Strand V, Boers M, Idzerda L, Kirwan JR, Kvien TK, Tugwell PS, et al. It's good to feel better but it's better to feel good and even better to feel good as soon as possible for as long as possible. Response criteria and the importance of change at OMERACT 10. J Rheumatol. 2011:38:1720-7.

9. Smolen JS, Landewe R, Breedveld FC, Buch M, Burmester G, Dougados M, et al. EULAR recommendations for the management of rheumatoid arthritis with synthetic and biological disease-modifying antirheumatic drugs: 2013 update. Ann Rheum Dis. 2014;73:492-509.

10. O'Dell JR. Therapeutic strategies for rheumatoid arthritis. N Engl J Med. 2004:350:2591-602.

11. Bathon JM, Cohen SB. The, American College of Rheumatology recommendations for the use of nonbiologic and biologic disease-modifying antirheumatic drugs in rheumatoid arthritis: where the rubber meets the road. Arthritis Rheum. 2008;2008(59):757-9.

12. Saag KG, Teng GG, Patkar NM, Anuntiyo J, Finney C, Curtis JR, et al. American College of Rheumatology 2008 recommendations for the use of nonbiologic and biologic disease-modifying antirheumatic drugs in rheumatoid arthritis. Arthritis Rheum. 2008;59:762-84

13. Meyer DM, Jesson MI, Li X, Elrick MM, Funckes-Shippy CL, Warner JD, et al. Anti-inflammatory activity and neutrophil reductions mediated by the JAK1/JAK3 inhibitor, CP-690,550, in rat adjuvant-induced arthritis. J Inflamm (Lond). 2010;7:41.

14. Kremer JM, Cohen S, Wilkinson BE, Connell CA, French JL, Gomez-Reino J, et al. A phase Ilb dose-ranging study of the oral JAK inhibitor tofacitinib (CP-690,550) versus placebo in combination with background methotrexate in patients with active rheumatoid arthritis and an inadequate response to methotrexate alone. Arthritis Rheum. 2012;64:970-81.

15. Kremer JM, Bloom BJ, Breedveld FC, Coombs JH, Fletcher MP, Gruben D, et al, The safety and efficacy of a JAK inhibitor in patients with active rheumatoid arthritis: results of a double-blind, placebo-controlled phase lla trial of three dose levels of CP-690,550 versus placebo. Arthritis Rheum. 2009;60:1895-905.
16. Fleischmann R, Cutolo M, Genovese MC, Lee EB, Kanik KS, Sadis S, et al. Phase Ilb dose-ranging study of the oral JAK inhibitor tofacitinib (CP-690,550) or adalimumab monotherapy versus placebo in patients with active rheumatoid arthritis with an inadequate response to disease-modifying antirheumatic drugs. Arthritis Rheum. 2012;64:617-29.

17. Tanaka $Y$, Suzuki M, Nakamura H, Toyoizumi S, Zwillich SH. Phase II study of tofacitinib (CP-690,550) combined with methotrexate in patients with rheumatoid arthritis and an inadequate response to methotrexate. Arthritis Care Res (Hoboken). 2011;63:1150-8.

18. Tanaka Y, Takeuchi T, Yamanaka H, Nakamura H, Toyoizumi S, Zwillich S. Efficacy and safety of tofacitinib as monotherapy in Japanese patients with active rheumatoid arthritis: a 12-week randomized, phase 2 study. Mod Rehumatol. 2015:25:514-21.

19. Lee EB, Fleischmann R, Hall S, Wilkinson B, Bradley J, Gruben D, et al. Tofacitinib versus methotrexate in rheumatoid arthritis. N Engl J Med. 2014;370:2377-86.

20. Burmester GR, Blanco R, Charles-Schoeman C, Wollenhaupt J, Zerbini C, Benda $B$, et al. Tofacitinib (CP-690,550) in combination with methotrexate in patients with active rheumatoid arthritis with an inadequate response to tumour necrosis factor inhibitors: a randomised phase 3 trial. Lancet. 2013;381:451-60.

21. Fleischmann R, Kremer J, Cush J, Schulze-Koops H, Connell CA, Bradley JD, et al. Placebo-controlled trial of tofacitinib monotherapy in rheumatoid arthritis. N Engl J Med. 2012;367:495-507.

22. van der Heijde D, Tanaka Y, Fleischmann R, Keystone E, Kremer J, Zerbini C, et al. Tofacitinib (CP-690,550) in patients with rheumatoid arthritis receiving methotrexate: Twelve-month data from a twenty-four-month phase II randomized radiographic study. Arthritis Rheum. 2013;65:559-70.

23. van Vollenhoven RF, Fleischmann R, Cohen S, Lee EB, García Meijide JA, Wagner $\mathrm{S}$, et al. Tofacitinib or adalimumab versus placebo in rheumatoid arthritis. N Engl J Med. 2012;367:508-19.

24. Kremer J, Li ZG, Hall S, Fleischmann R, Genovese M, Martin-Mola E, et al. Tofacitinib in combination with nonbiologic DMARDs in patients with active rheumatoid arthritis: a randomized trial. Ann Intern Med. 2013;159:253-61.

25. Wollenhaupt J, Silverfield J, Lee EB, Curtis JR, Wood SP, Soma K, et al. Safety and efficacy of tofacitinib, an oral Janus kinase Inhibitor, for the treatment of rheumatoid arthritis in open-label, long-term extension studies. J Rheumatol. 2014:41:837-52.

26. Wollenhaupt J, Silverfield J, Lee EN, Terry K, Kwok K, Lazariciu I, et al. Tofacitinib, an oral Janus kinase inhibitor, in the treatment of rheumatoid arthritis: safety and clinical and radiographic efficacy in open-label, long-term extension studies over 7 years. Arthritis Rheum. 2015;67(suppl 10):abs 1645.

27. Wells GA, Tugwell P, Kraag GR, Baker PR, Groh J, Redelmeier DA. Minimum important difference between patients with rheumatoid arthritis: the patient's perspective. J Rheumatol. 1993;20:557-60

28. Wells G, Li T, Maxwell L, Maclean R, Tugwell P. Determining the minimal clinically important differences in activity, fatigue, and sleep quality in patients with rheumatoid arthritis. J Rheumatol. 2007;34:280-9.

29. Farrar JT, Young Jr JP, LaMoreaux L, Werth JL, Poole RM. Clinical importance of changes in chronic pain intensity measured on an 11-point numerical pain rating scale. Pain. 2001;94:149-58.

30. Dworkin RH, Turk DC, Wyrwich KW, Beaton D, Cleeland CS, Farrar JT, et al. Interpreting the clinical importance of treatment outcomes in chronic pain clinical trials: IMMPACT recommendations. J Pain. 2008;9:105-21.

31. Boyle MH, Furlong W, Feeny D, Torrance GW, Hatcher J. Reliability of the Health Utilities Index-Mark III used in the 1991 cycle 6 Canadian General Social Survey Health Questionnaire. Qual Life Res. 1995;4:249-57.

32. Kosinski M, Zhao SZ, Dedhiya S, Osterhaus JT, Ware Jr JE. Determining minimally important changes in generic and disease-specific health-related quality of life questionnaires in clinical trials of rheumatoid arthritis. Arthritis Rheum. 2000:43:1478-87.

33. Strand V, Bombardier C, Maetzel A. Use of minimum clinically important differences $[\mathrm{MCID}]$ in evaluating patient responses to treatment of RA [abstract]. Arthritis Rheum. 2001;44:S187.

34. Strand V, Cannon G, Cohen S, Ware J. Correlation of HAQ with SF-36; comparison of leflunomide to methotrexate in patients with active RA [abstract]. Arthritis Rheum. 2001:44:S187.

35. Zhao SZ, Fiechtner J, Tindall EA, Dedhiya SD, Zhao WW, Osterhaus JT, et al. Evaluation of health-related quality of life of rheumatoid arthritis patients treated with celecoxib. Arthritis Care Res. 2000;13:112-21.

36. Tugwell P, Wells G, Strand V, Maetzel A, Bombardier C, Crawford B, et al. Clinical improvement as reflected in measures of function and health-related 
quality of life following treatment with leflunomide compared with methotrexate in patients with rheumatoid arthritis: sensitivity and relative efficiency to detect a treatment effect in a twelve-month, placebo-controlled trial. Leflunomide Rheumatoid Arthritis Investigators Group. Arthritis Rheum. 2000:43:506-14.

37. Wells G, Li T, Maxwell L, Maclean R, Tugwell P. Responsiveness of patient reported outcomes including fatigue, sleep quality, activity limitation, and quality of life following treatment with abatacept for rheumatoid arthritis. Ann Rheum Dis. 2008;67:260-5.

38. Ware JE, Kosinski M, Dewey JE. How to score version two of the SF 36 Health Survey. Lincoln, Rl: Quality Metric, Incorporate; 2000.

39. Strand V, Crawford B, Singh J, Choy E, Smolen JS, Khanna D. Use of "spydergrams" to present and interpret SF-36 health-related quality of life data across rheumatic diseases. Ann Rheum Dis. 2009;68:1800-4.

40. Pincus T. Are patient questionnaire scores as "scientific" as laboratory tests for rheumatology clinical care? Bull NYU Hosp Jt Dis. 2010;68:130-9.

41. Carr A, Hewlett S, Hughes R, Mitchell H, Ryan S, Carr M, et al. Rheumatology outcomes: the patient's perspective. J Rheumatol. 2003;30:880-3.

42. Dickens C, McGowan L, Clark-Carter D, Creed F. Depression in rheumatoid arthritis: a systematic review of the literature with meta-analysis. Psychosom Med. 2002;64:52-60

43. Uguz F, Akman C, Kucuksarac S, Tufekci O. Anti-tumor necrosis factor-alpha therapy is associated with less frequent mood and anxiety disorders in patients with rheumatoid arthritis. Psychiatry Clin Neurosci. 2009;63:50-5.

\section{Submit your next manuscript to BioMed Central and take full advantage of:}

- Convenient online submission

- Thorough peer review

- No space constraints or color figure charges

- Immediate publication on acceptance

- Inclusion in PubMed, CAS, Scopus and Google Scholar

- Research which is freely available for redistribution 